\title{
A New Maximum Power Point Tracking Technique for Permanent Magnet Synchronous Generator Based Wind Energy Conversion System
}

Authors:

Yuanye Xia+, Khaled H. Ahmed*, Barry W. Williams+

Organization:

+Department of Electronic and Electrical Engineering, Strathclyde University, Glasgow, UK

*Electrical Engineering Department, Faculty of Engineering, Alexandria University, Alexandria, Egypt.

Corresponding author:

Yuanye Xia

Email: yuanye.xia@eee.strath.ac.uk

Address:

Royal College Building, 204 George Street, Glasgow, G1 1XW

Keywords: MPPT, PMSG, power coefficient, wind energy

Abstract: A new maximum power point tracking technique for permanent magnet synchronous generator based wind energy conversion systems is proposed. The technique searches for the system optimum relationship for maximum power point tracking and then controls the system based on this relationship. The validity of the technique is theoretically analysed, and the design procedure is presented. The primary merit of the proposed technique is that it does not require an anemometer or 
pre-knowledge of a system, but has an accurate and fast response to wind speed fluctuations. Moreover, it has the ability of online updating of time-dependant turbine or generator parameter shift. The validity and performance of the proposed technique is confirmed by MATLAB/Simulink simulations and experimentations.

\section{Introduction}

The demand for electricity power is growing rapidly and is expected to keep growing. According to the Energy Information Administration (EIA) in the U.S., from 1990 to 2007, growth in net electricity generation outpaced the growth in total energy consumption. Meanwhile, it is estimated that the world net electricity generation will increase by $87 \%$ in the Reference case, from 18.8 trillion kilowatt-hours in 2007 to 35.2 trillion kilowatt-hours in 2035 , at an average annual rate of $2.3 \%$ [1]. Due to escalating oil prices and $\mathrm{CO}_{2}$ emission reduction demand, renewable energy, especially wind energy, becomes more and more attractive and competitive.

Wind energy can be captured and transformed to electric energy using a wind turbine and electric generator. Due to wind energy and turbine features, optimum wind energy extraction can be achieved by operating the wind turbine in a variable-speed mode. At a given wind speed, the efficiency is drastically affected by the turbine's tip speed ratio (TSR), which is defined as the ratio between the rotor speed of the tip of a blade and the actual wind velocity. There is an optimum TSR at which the maximum energy conversion efficiency is achieved [2]. A typical power efficiency versus TSR curve is shown in Fig. 1. 


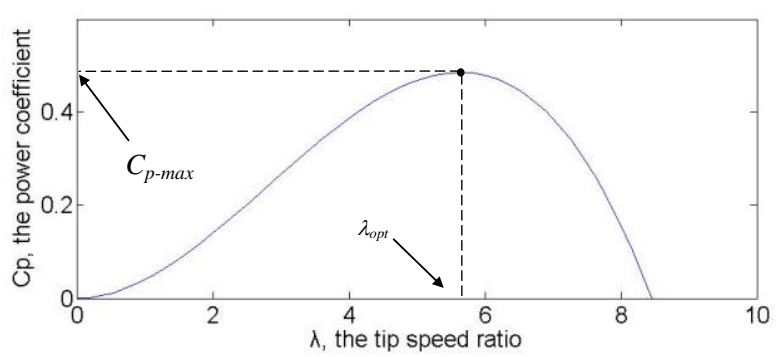

Fig.1. A typical power coefficient curve

A maximum power point tracking (MPPT) algorithm increases the power conversion efficiency by regulating the turbine rotor speed according to actual wind speeds. Therefore an effective and low implementation cost MPPT algorithm is essential to enhance the efficiency and economics of wind energy conversion systems (WECS).

Basically there are three types of MPPT algorithms, namely, tip speed ratio (TSR) control, perturb and observe $(\mathrm{P} \& \mathrm{O})$ control (which is also known as hill-climbing searching (HCS) control), and optimum relationship based (ORB) control [3][4].

TSR control directly regulates the turbine speed to keep the TSR at an optimal value by measuring wind speed and turbine speed [5]-[9]. The control strategy is straightforward. In [6], a fuzzy logic controller is used instead of regular PID controller to control the optimum rotor speed. No detailed mathematical model or linearization about an operating point is needed and it is insensitive to system parameter variation. In [7] turbine pitch angle is regulated according to the measured wind speed. Neural network and fuzzy logic control are employed to improve the performance. Due to the turbine and other system element aging, the value of optimum TSR may vary. An adaptive strategy is shown to improve the performance [8] and its stability is discussed in [9]. In summary, TSR control has good performance with fast response and high efficiency. However, an accurate 
anemometer is expensive and adds extra cost to the system, especially for small scale WECSs. Moreover, it presents a number of difficulties in practical implementation. For example, the wind velocity close to the turbine is different from the free stream velocity [10], and due to gust and turbulence, extra processing of the wind speed measurement must be incorporated. Furthermore, the optimum TSR is dependent on the system characteristics and should be obtained in advance.

P\&O control adjusts the turbine speed towards the MPP, according to the result of comparison between successive wind turbine generator output power measurements [11]-[15]. It is especially suitable for small scale WECSs, as an anemometer is not required and the system knowledge is not needed. Therefore the system has high reliability, low complexity and cost. The authors in [11] discussed the critical control parameters in P\&O control. Fuzzy logic control is used in [12][13] for efficiency optimization and performance enhancement. It provides fast convergence, and accepts noisy and inaccurate signals. In [14], the duty ratio of a DC/DC converter is directly adjusted, and the adjustments are implemented through a relationship found between the change in output power and the duty ratio. However, the $\mathrm{P} \& \mathrm{O}$ control suffers from some common drawbacks. The response to wind speed change is extremely slow, especially for large inertia wind turbines [16][17]. Rapidly fluctuating character of wind supply makes the situation even worse. Oscillation around the optimum point is also inevitable. All these drawbacks can significantly lower MPPT efficiency and may even cause oscillation in the system. Therefore most $\mathrm{P} \& \mathrm{O}$ controllers are implemented in small scale WECSs. 
ORB control assures MPPT with the aid of knowledge of optimum relationships between system parameters [18]-[31]. Wind speed measurement is not required and the response to wind speed change is fast. Therefore it is a mature technique for applications of different power ratings. The power versus rotor speed relationship is used in [18]-[23][41], and the power versus rectifier dc voltage relationship is used in [24]. These control strategies are also known as power signal feedback control [3]. Other optimum relationships not including a power signal have also been proposed. In [23][25]-[28], the relationship between electrical torque and rotor speed is employed to track MPP. In order to further simplify control, rectifier dc voltage versus dc current relationship is used in [23][29]-[31]. Although ORB control is widely used in wind WECSs, the main drawback is that system pre-knowledge is required, which varies from one system to the other. The knowledge is obtained via simulation and lab tests, and should be further corrected by field tests. Moreover, parameter shift caused by the system aging may affect MPPT efficiency. Additionally, ORB control may consume a lot of memory space [32].

An alternative method for MPPT is proposed in [3]. A microcontroller is utilized to save the optimum power versus dc voltage relationship obtained by $\mathrm{P} \& \mathrm{O}$ control. No anemometer is required and it is suitable for large inertia systems. However, significant off-line experimentation is required as the maximum power points for every dc voltage value need to be tested and recorded. In [31], the authors proposed a method to find the optimum relationship between voltage and current, by obtaining one voltage and current pair, $\left(V_{d c}, I_{d c}\right)$, of the relationship first, using normal P\&O control. Then the relationship is obtained by calculation. However, the method is 
implemented assuming steady wind conditions, therefore impractical in actual application.

In this paper, a new MPPT technique combining P\&O and ORB control, for permanent magnet synchronous generator (PMSG) based WECSs, is proposed. It does not need an anemometer or system pre-knowledge. The optimum relationship between rectified dc voltage and current [23][29]-[31] is rapidly obtained by advanced $\mathrm{P} \& \mathrm{O}$ control. Then the system is controlled using conventional ORB control. Unlike the method proposed in [3], no off-line experiments are required and the accurate optimum relationship can be rapidly obtained in variable wind conditions. Its validity is confirmed by MATLAB/Simulink simulations.

The paper is organized in seven sections. Section I introduces the conventional MPPT methods. In section II, the system configuration for investigation is presented. Section III describes the characteristic of WECS and establishes the effectiveness of the optimum relationship of rectified dc voltage and current for MPPT. In section IV, a new MPPT technique is proposed, and presented in details. The simulation results demonstrate the validity of the new technique in section V. Experimental implementation to verify the proposed technique is represented in section VI. Section VII discusses the extension of the technique to other topologies and systems.

\section{System configuration}

The scheme of the WECS, where the proposed algorithm is implemented, is shown in Fig.2 [33]. The PMSG is coupled directly to a three-blade, horizontal axis wind turbine. Pitch control can be applied when the output power exceeds the rated value 
or the maximum turbine rotor speed is reached [42][43]. Because the PMSG has a high efficiency and does not require for a gear box and external excitation current, it is favoured in WECS [34]. The output power transfers through an AC-DC-AC stage, which consists of a diode bridge rectifier, a boost converter, and a grid-side inverter, which is connected to the grid. Due to the low cost and high reliability of diode bridge rectifier, it is employed instead of a controlled rectifier. A boost converter controls the dc side voltage and current for MPPT, and steps up the voltage for grid connection. Finally, the captured power is transferred to the grid via an inverter. The scheme in Fig.2 is used in this paper to demonstrate the validity of the new MPPT technique because of its simplicity and clarity.

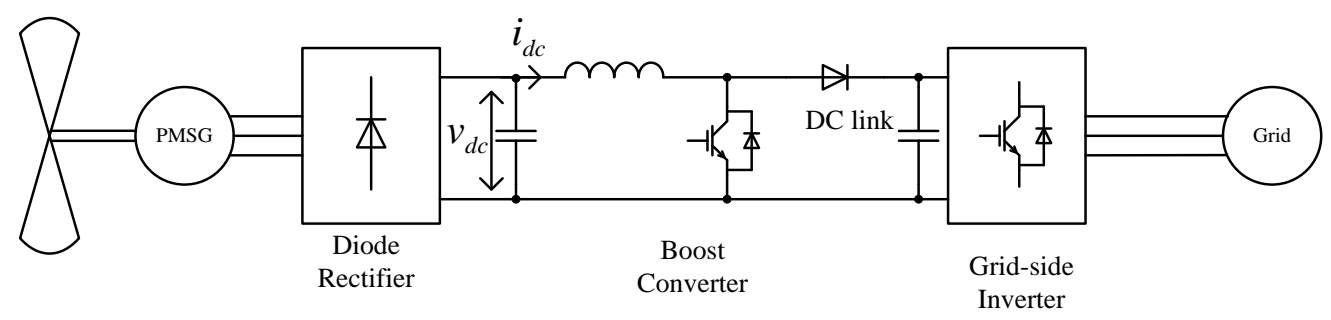

Fig.2 A normal wind energy conversion system

\section{Wind energy conversion system characteristics}

\section{A. Mechanical characteristics}

The energy derived from wind by the wind turbine is expressed as [35]

$$
P=\frac{1}{2} \rho C_{p} A v_{w}^{3}
$$

where $\rho$ is the air density, $A$ is the wind turbine swept area, $v_{w}$ is the wind speed and $C_{p}$ is the power coefficient. $C_{p}$ is a nonlinear function of tip speed ratio, $\lambda$, if the turbine pitch angle is fixed. $\lambda$ is defined as

$$
\lambda=\frac{r \Omega}{v_{w}}
$$


where $r$ is the rotor radius, $\Omega$ is the turbine rotor speed. A typical $C_{p^{-}} \lambda$ curve is shown in Fig.1. There is an optimum $\lambda_{o p t}$, at which the power efficient is maximum. $C_{p-\max }$ are fixed values for a given wind turbine.

From equation (1) and (2), it can be concluded that

$$
P_{\max } \propto v_{w}^{3} \propto \Omega_{o p t}^{3}
$$

where $\Omega_{\text {opt }}$ is the optimum rotor speed at a given wind speed.

\section{B. Electrical characteristics}

For a PMSG with a constant flux, the phase back electromotive force, $E$, is a linear function of generator rotor speed [36], which equals the turbine rotor speed,

$$
E=K_{e} \Phi \Omega
$$

where $\Phi$ is the generator flux and $K_{e}$ is a coefficient.

The phase terminal voltage function for a non-salient PMSG is written as

$$
\begin{gathered}
V_{a c}=E-I_{a c}\left(R_{s}+j \Omega_{e} L_{s}\right) \\
\Omega_{e}=p \Omega
\end{gathered}
$$

where $V_{a c}$ is the phase terminal voltage, $I_{a c}$ is the phase current, $R_{s}$ is the stator resistance, $L_{s}$ is the stator inductance, $\Omega_{e}$ is electrical angular frequency, and $p$ is the number of pole pairs.

Due to the diode bridge rectifier, the ac side voltage amplitude $V_{a c-a m p}$ and dc side voltage $V_{d c}$ can be expressed as [37]

$$
V_{d c}=\frac{3 \sqrt{3}}{\pi} V_{a c-a m p}
$$

From equations (4) to (6), there is the approximate relationship

$$
V_{d c} \propto \Omega
$$

When the system is at MPP,

$$
V_{d c-o p t} \propto \Omega_{o p t}
$$


where $V_{d c-o p t}$ is the optimum rectified dc voltage at a given wind speed.

Equations (3) and (8) give

$$
P_{\max } \propto V_{d c-o p t}^{3}
$$

Meanwhile, the maximum dc side electric power at a given wind speed can be expressed as

$$
P_{d c}=\eta P_{\max }=V_{d c-o p t} I_{d c-o p t}
$$

where $\eta$ is the conversion efficiency from the generator to the dc side, and is assumed to be a fixed value. $I_{d c-o p t}$ is the optimum dc side current.

From equations (9) and (10), at the maximum power point, the following relationship is valid.

$$
I_{d c-o p t} \propto V_{d c-o p t}^{2}
$$

Equation (11) can be expressed as

$$
I_{d c-o p t}=k V_{d c-o p t}^{2}
$$

Equation (12) is the optimum relationship used for ORB control in this paper.

If $V_{d c-o p t}{ }^{2}$ is considered a variable, $I_{d c-o p t}$ is a linear function of $V_{d c-o p t}{ }^{2}, k$ is the corresponding slope, and equation (12) is written as

$$
I_{d c-o p t}=f\left(V_{d c-o p t}^{2}\right)
$$

Fig.3(a) shows the curves of $I_{d c}$ vs. $V_{d c}^{2}$ at different wind speeds, which are labelled as $v_{w 1}, v_{w 2}$ and $v_{w 3}$, respectively. The dotted line in Fig.3(a) is the optimum relationship between $I_{d c}$ and $V_{d c}{ }^{2}$ obtained from simulation. The points of intersection, such as $\left(V_{d c 1^{2}}^{\prime}, I_{d c 1}^{\prime}\right),\left(V_{d c 2^{2}}^{\prime}, I_{d c 2}^{\prime}\right)$ and $\left(V_{d c 3^{2}}^{\prime}, I_{d c 3}^{\prime}\right)$, are the actual MPPs at specific wind speeds. The solid line is the proposed linear equation (12), which approximates the actual nonlinear optimum relationship. The points of intersection, such as $\left(V_{d c 1}{ }^{2}, I_{d c 1}\right)$, $\left(V_{d c 2^{2}}, I_{d c 2}\right)$ and $\left(V_{d c 3^{2}}{ }^{2} I_{d c 3}\right)$, are the operating points when applying equation (12) for MPPT. The power vs. $V_{d c}$ curve of these wind speeds, $v_{w 1}, v_{w 2}$ and $v_{w 3}$, are shown in 
Fig.3(b). $P^{\prime}{ }_{1}, P^{\prime}{ }_{2}$ and $P^{\prime}{ }_{3}$ are the actual maximum power, while $P_{1}, P_{2}$ and $P_{3}$ are the output power when applying equation (12) for MPPT. It can be observed that the power difference is small, thus can be neglected.

Figs.3 (a) and (b) proves that the equation (12) is valid for MPPT. There are two main reasons. First, in modern PMSG the terminal voltage varies linearly with rotor speed [38][39]. More importantly, observing the $C_{p}$ curve as shown in Fig.1, the curve near the MPP is flat-topped, and there is relatively large margin for error in the MPPT accuracy, where the power transfer efficiency of the system will not be greatly affected [11][40].
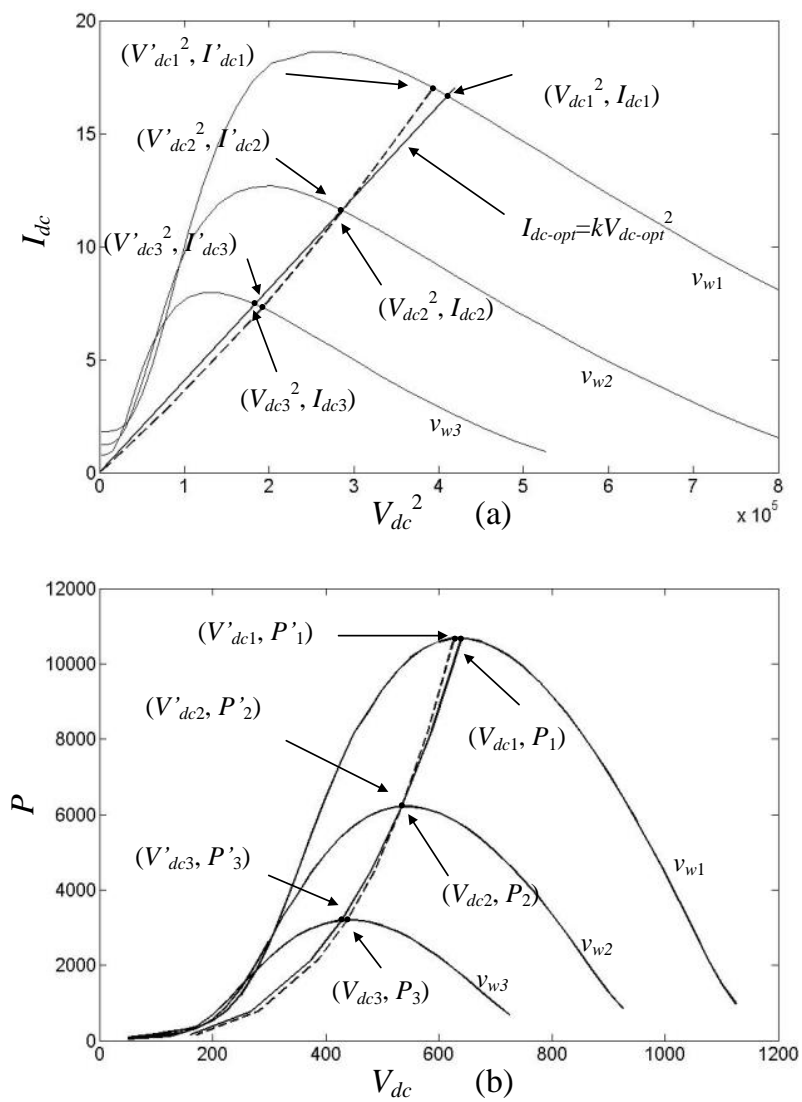

Fig.3 Wind energy electrical characteristics. (a) The $I_{d c}$ vs. $V_{d c}{ }^{2}$ curves for different wind speeds. (b) The $P$ vs. $V_{d c}$ curves for different wind speeds. 


\section{The proposed MPPT technique}

The proposed MPPT technique has two control modes, namely a training mode and a routine mode. The training mode searches for the optimum relationship, given by equation (12). The routine mode is conventional ORB control based on the obtained optimum relationship. The control block diagrams are shown in Fig.4. Only dc voltage and current are measured for MPPT.

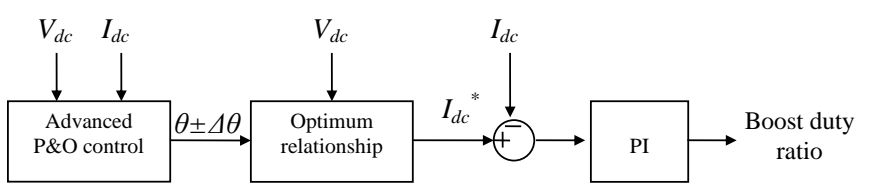

(a)

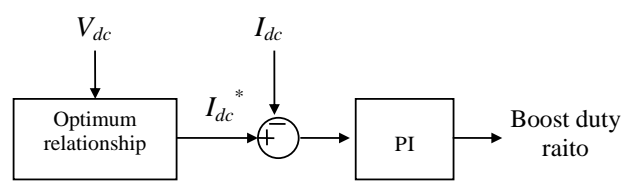

(b)

Fig. 4 System control block diagrams. (a) Control block diagram for the training mode. (b) Control block diagram for the routine mode.

In the training mode, as shown in Fig. 5, Line A is the optimum relationship which is unknown, and Line B is an arbitrary line initially used. Equation (12) is rewritten as

$$
I_{d c-o p t}=(a \tan \theta) V_{d c-o p t}^{2}
$$

Considering the values of $V_{d c}{ }^{2}$ and $I_{d c}$ are of different orders of magnitude, $a$ in equation (14) is introduced to match their values. Advanced P\&O control is used to search for the optimum relationship by changing the $\theta$ value according to the result of the comparison of successive output powers. Observing Figs.3(a) and 5, it can be concluded that, for a given wind speed, the power is always larger when $\theta$ is closer to $\theta_{\text {opt }}$, and this is demonstrated as the follows.

Considering Power vs. $V_{d c}$ depicted in Fig.3(b), 


$$
\begin{aligned}
& \left.\frac{d P}{d V_{d c}}\right|_{V_{d c}=V_{d c-o p t}}=0 \\
& \left.\frac{d P}{d V_{d c}}\right|_{V_{d c}>V_{d c-o p t}}<0 \\
& \left.\frac{d P}{d V_{d c}}\right|_{V_{d c}<V_{d c-o p t}}>0
\end{aligned}
$$

Observing Fig.5, at a given wind speed it can be concluded that

$$
\frac{d V_{d c}}{d \theta}<0
$$

Also applying the chain rule

$$
\begin{gathered}
\frac{d P}{d \theta}=\frac{d P}{d V_{d c}} \frac{d V_{d c}}{d \theta} \\
\left.\frac{d P}{d \theta}\right|_{\theta=\theta_{o p t}}=\left.\frac{d P}{d V_{d c}}\right|_{V_{d c}=V_{d c-o p t}} \times \frac{d V_{d c}}{d \theta} \\
\left.\frac{d P}{d \theta}\right|_{\theta<\theta_{o p t}}=\left.\frac{d P}{d V_{d c}}\right|_{V_{d c}>V_{d c-o p t}} \times \frac{d V_{d c}}{d \theta} \\
\left.\frac{d P}{d \theta}\right|_{\theta>\theta_{o p t}}=\left.\frac{d P}{d V_{d c}}\right|_{V_{d c}<V_{d c-o p t}} \times \frac{d V_{d c}}{d \theta}
\end{gathered}
$$

Considering equations (15) to (17), it holds that

$$
\begin{aligned}
& \left.\frac{d P}{d \theta}\right|_{\theta=\theta_{\text {opt }}}=0 \\
& \left.\frac{d P}{d \theta}\right|_{\theta<\theta_{\text {opt }}}>0 \\
& \left.\frac{d P}{d \theta}\right|_{\theta>\theta_{\text {opt }}}<0
\end{aligned}
$$

Thus the function $P(\theta)$ has a single extreme point. So $\mathrm{P} \& \mathrm{O}$ control is valid to search for maximum power by perturbing $\theta$. 
Once $\theta_{\text {opt }}$ is obtained, which means the optimum relationship of (14) is known by the system, the routine mode starts and the system is controlled as by conventional ORB control.

Due to the system elements aging, such as with the wind turbine and generator, any optimum relationship may vary, affecting the wind energy capture efficiency. Online updating can be implemented by running the training mode again after a long period operation.

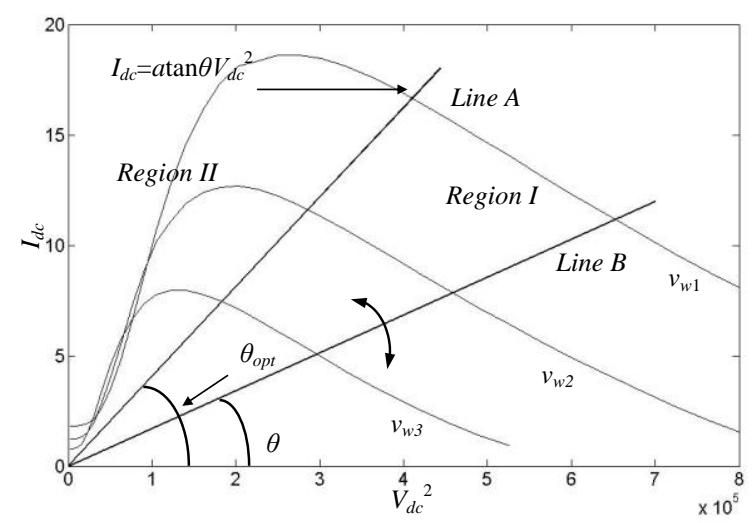

Fig.5 The curves of $I_{d c}$ vs. $V_{d c}^{2}$ at different wind speed and the linear equation

\section{A. Training mode}

For simplicity, in Fig.5, the area where $\theta$ is less than $\theta_{\text {opt }}$ is labelled Region I (the bottom right part to Line A), and the other area is labelled Region II (the top left part to Line A).

Some important system features should be high lightened to help design the advanced $\mathrm{P} \& \mathrm{O}$ controller.

- With a given wind speed, the power is always larger when $\theta$ is closer to $\theta_{\text {opt }}$. 
- Theoretically, $\theta$ should always go one direction until it reaches $\theta_{\text {opt }}$ as it is independent of wind speeds. In other words, if $\theta$ is in Region I, then it will always remain in Region I until it reaches $\theta_{\text {opt }}$.

- The searching speed of the training process is not a main concern as it only operates once.

\section{Initialization}

When the wind speed is above the cut-in wind speed, the turbine is started up by using a conventional start-up control method that does not employ an anemometer. Thus before the proposed MPPT is applied, the turbine already has an initial rotor speed. In the initialization block in Fig.6, $a$ and the initial $\theta$ in equation (14) are determined. Theoretically, $a$ and the initial $\theta$ can be arbitrary values, because an accurate value of $a \tan \theta$ is obtained via the perturbation of $\theta$. However, for a better performance during the training mode, a method to determine $a$ and initial $\theta$ values is suggested.

Since $a$ is used to match the values of $V_{d c}{ }^{2}$ and $I_{d c}$, a simple and effective assignment method is to use the ratio of rated values of $V_{d c}{ }^{2}$ and $I_{d c}$ of a given WECS as the value of $a$, which is expressed as

$$
a=\frac{I_{d c-\text { rated }}}{V_{d c-\text { rated }}^{2}}
$$

For the initial $\theta$ value, it is recommended to increase $\theta$ gradually to reach $\theta_{\text {opt }}$ rather than decrease it, because the power increase is much smoother in Region I than in Region II, as shown in Fig.5. Therefore, the initial $\theta$ should be a value smaller than $\theta_{o p t}$, to guarantee being in Region I. For a mature WECS design, it is safe to assume that the rated $V_{d c}{ }^{2}$ and $I_{d c}$ is close to the MPP at a certain wind speed. Therefore, if $a$ is determined by equation (19), it can also be assumed that $\theta_{\text {opt }}$ is a value close to $45^{\circ}$. 
Hence the initial $\theta$ can be half or one-third of the estimated $\theta_{\text {opt }}$, or even smaller. Of course, the determination of $a$ and initial $\theta$ can also be obtained by simulation. Note that in the following presentation of the proposed MPPT technique, the initial $\theta$ is assumed to be a value smaller than $\theta_{\text {opt }}$ and lies in Region I.

\section{Evaluate wind condition}

Each time the system starts to change $\theta$, the wind condition should first be evaluated. The system will not change $\theta$ unless the wind speed is stable. Thereby the effect of an unstable wind condition during the $\mathrm{P} \& \mathrm{O}$ process can be significantly minimized. As previously mentioned, the training mode only operates once, thus the correct perturbation is much more important than the search speed.

A simple method is to continue evaluating the difference of successive samples of output power, $\Delta P_{\text {out }}$. Defining an index, steady_mark, as

$$
\text { steady_mark }=\frac{\Delta P_{\text {out }}}{P_{\text {out }}}
$$

If the steady_mark is smaller than a threshold, then it can be assumed that the wind speed is stable and the $\mathrm{P} \& \mathrm{O}$ process can start.

\section{Determining the sign of $\Delta \theta$}

With a change of $\Delta \theta$, the corresponding change of power, $\Delta P$, is measured. If a previous positive $\Delta \theta$ results in an output power increase, then it means $\theta$ is still in Region I. Hence the next $\Delta \theta$ should still be positive, and vice versa. Such a basic $\mathrm{P} \& \mathrm{O}$ control can assure the $\theta$ goes in the right direction with a stable wind speed and gradually approaches $\theta_{\text {opt }}$. However, if there is a sudden drop of wind speed right after adjusting the $\theta$ value, a significant decrease of output power may 'fool' the $\mathrm{P} \& \mathrm{O}$ 
process into making a wrong decision. Such a condition slows down the search for the optimum relationship. Advanced $\mathrm{P} \& \mathrm{O}$ control is employed to minimize the influence.

As mentioned, theoretically, if the initial $\theta$ is in Region I, it should keep increasing until it reaches $\theta_{\text {opt }}$. This process is independent of wind speed. Therefore the signs of previous $\Delta \theta$ can help judge the current sign. It is logical to assume that if most of the previous $\Delta \theta$ are positive, which means $\theta$ is in Region $\mathrm{I}$, then it is highly probable that it is still in Region I even though the change of power shows that it may now be in Region II.

To achieve such a concept, the previous signs of $\Delta \theta$ are recorded in an array $\operatorname{sign}[n]$ $(n>0)$, where $n$ is the number of previous $\Delta \theta$. If a previous $\Delta \theta$ is in Region I, then its sign is labelled as +1 , otherwise it is labelled as -1 , as shown in (21).

$$
\operatorname{sign}[n]=\left\{\begin{array}{l}
+1(\text { In Region I }) \\
-1(\text { In Region II })
\end{array} \quad n>0\right.
$$

According to the comparison of successive output power, the present $\operatorname{sign}[0]$ is also judged and obtained, where 0 means it is the current sign. Labelled in the same way, as shown in (22)

$$
\operatorname{sign}[0]=\left\{\begin{array}{l}
+1(\text { In Region } \mathrm{I}) \\
-1(\text { In Region II })
\end{array}\right.
$$

The sum of the $\operatorname{sign}[n](n \geq 0)$

$$
R=\sum_{k=0}^{n} \operatorname{sign}[k]
$$

If $R>0$, more than half of the previous $\Delta \theta$ are positive, then it is highly possible that the current $\theta$ still lies in Region I, and the next $\Delta \theta$ should be positive. Otherwise, if $R<0, \Delta \theta$ should be negative. Then the array $\operatorname{sign}[n]$ is updated as shown in equation (24), for the next time. 


$$
\begin{gathered}
\operatorname{sign}[n]=\operatorname{sign}[n-1] \\
\bullet \\
\bullet \\
\operatorname{sign}[1]=\operatorname{sign}[0]
\end{gathered}
$$

Using such a method, unless the $\theta$ lies in Region II, otherwise, a sudden wind change does not affect $R$, and $\theta$ will keep changing in correct direction. And if $\theta$ lies in Region II, then more and more negative $\operatorname{sign}[n]$ appears and finally $R<0$. Therefore, this method can effectively minimize the influence of wind speed change.

The value of $n$ represents the ability of resistance to the successive wind speed drops. For example, if $n=2$, then two successive wind speed drops may cause an incorrect $\theta$ change direction, and if $n=4$, then three successive wind speed drops may cause misjudgement. However, with the increase of $n$, the system response slows down as it needs more steps to confirm which region $\theta$ really lies in. Therefore the value of $n$ is a trade-off of search accuracy and speed. Considering that $\theta$ only varies when the wind speed is stable, such successive sudden wind speed drop situation is rare. Thus $n$ can be a small value, i.e. 4 or 6 . It should be noted that $n$ must be an even number, so the sum of the $\operatorname{sign}[n](n \geq 0)$ never equals to zero. The combination of the control strategy in Section IV-A-2 and Section IV-A-3 makes the P\&O process robust and accurate in actual fluctuating wind conditions.

\section{Determining the amplitude of $\Delta \theta$}

The amplitude of $\Delta \theta$ is then determined as shown in Fig.6. When $\theta$ is around $\theta_{o p t}$, it starts to oscillate. Therefore, the amplitude of $\Delta \theta$ should be reduced gradually, then 
the oscillation range will also be reduced, and finally $\theta$ converges to $\theta_{\text {opt }}$. Once the optimum relationship is obtained, the training mode ends and routine mode starts. An array amplitude $[m](m>0)$ is introduced to control the amplitude of $\Delta \theta$. Similar to $\operatorname{sign}[n]$, it is related to previous $m \Delta \theta$, and labelled in a similar way.

$$
\text { amplitude }[m]=\left\{\begin{array}{l}
+1(\text { In Region I) } \\
-1(\text { In Region II) }
\end{array} \quad m>0\right.
$$

Every time a change of $\theta$ occurs, the array amplitude $[m]$ is updated as follows,

$$
\begin{aligned}
\operatorname{amplitude}[m]= & \operatorname{amplitude}[m-1] \\
& \bullet \\
& \bullet \\
& \bullet \\
\text { amplitude }[1] & =\text { amplitude }[0]
\end{aligned}
$$

And the amplitude[0]=+1, if the system confirms that the current $\theta$ still lies in Region I, or amplitude[0]=-1, if lying in Region II.

The amplitude of $\Delta \theta$ is expressed as

$$
\begin{gathered}
|\Delta \theta|=\frac{\sum_{k=1}^{m} \text { amplitude }[k]}{m} \theta_{f} \\
0 \leq \frac{\sum_{k=1}^{m} \text { amplitude }[k]}{m} \leq 1
\end{gathered}
$$

where $\theta_{f}$ is the fundamental amplitude value. Initially, amplitude $[k]=+1(k=0,1,2, \ldots, m)$ and $\sum_{k=1}^{m}$ amplitude $[k]=m$. Therefore $|\Delta \theta|=\theta_{f}$, and $\theta$ approaches $\theta_{\text {opt }}$ with a relatively large amplitude. Once $\theta$ is larger than $\theta_{\text {opt }}$ and lies in Region II, the value of $\sum_{k=1}^{m}$ amplitude $[k]$ begins to decrease, leading to a smaller amplitude. When $\theta$ oscillates around $\theta_{\text {opt }}, \Delta \theta$ becomes smaller and smaller, with the number of -1 being close to the number of +1 . Also the oscillating band is gradually narrowed. Finally when the $\sum_{k=1}^{m}$ amplitude $[k]$ is smaller than a threshold, the system can confirm that the $\theta_{\text {opt }}$ has been achieved, and the training mode ends. 
The value of $m$ relates to the reducing rate of the $\Delta \theta$ amplitude. $m$ should be large enough, so that the $\Delta \theta$ amplitude will reduce gradually. The critical control parameters, $a$, initial $\theta$, steady_mark, $n, m$ and $\theta_{f}$ discussed in this section should be obtained via simulation to get the optimum performance. A flow chart of the proposed technique is shown in Fig.6.

\section{B. Routine mode \& online updating}

When the training mode ends, the optimum relationship of equation (14) is obtained. The system starts routine mode, tracks MPP using conventional ORB control. Moreover, due to system element aging and system parameter change, the obtained relationship may be no longer optimum. Online updating can be implemented by running the training mode again to search for the new optimum relationship.

\section{Comparison with conventional MPPT methods}

The proposed technique is compared to three conventional MPPT methods as shown in Table 1. The proposed MPPT technique has the main advantages of the conventional MPPT methods. Unlike the TSR method, it does not require an anemometer which is expensive especially for small scale WECSs. Its performance of fast tracking speed is similar to ORB control but does not require system preknowledge. Furthermore it has the ability of online updating by running the training mode again, like the P\&O method, but without oscillation around the MPP. 
Table 1 Comparison with traditional MPPT methods

\begin{tabular}{|c|c|c|c|l|c|}
\hline & Anemometer & $\begin{array}{c}\text { System } \\
\text { pre-knowledge }\end{array}$ & $\begin{array}{c}\text { Tracking } \\
\text { speed }\end{array}$ & $\begin{array}{l}\text { Oscillation } \\
\text { at MPP }\end{array}$ & $\begin{array}{c}\text { Online } \\
\text { updating }\end{array}$ \\
\hline TSR & Yes & Required & Fast & No & No \\
\hline P\&O & No & Not required & Slow & Yes & Yes \\
\hline ORB & No & Required & Fast & No & No \\
\hline $\begin{array}{c}\text { Proposed } \\
\text { technique }\end{array}$ & No & Not required & Fast & No & Yes \\
\hline
\end{tabular}




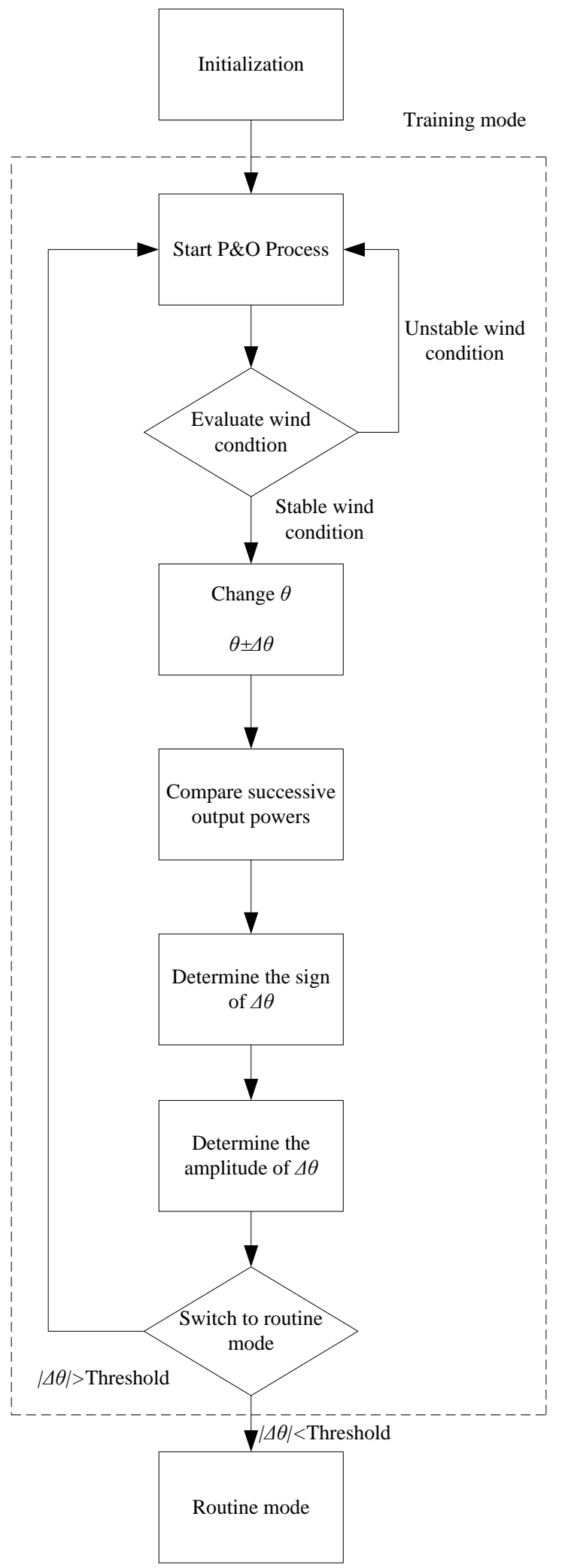

Fig.6 Proposed MPPT technique control flow chart 


\section{Simulation results}

MATLAB/Simulink simulations can verify the performance of the proposed MPPT technique. The WECS scheme is similar to that shown in Fig.2. The parameters of PMSG and wind turbine are summarized in Table 2, while the control parameters are summarized in Table 3.

Table 2 PMSG and wind turbine parameters in simulation

\begin{tabular}{|c|c|}
\hline Items & Specification \\
\hline Power rating & $10 \mathrm{~kW}$ \\
\hline Rated current & $11.8 \mathrm{~A}$ \\
\hline Rated voltage & $490 \mathrm{~V}$ \\
\hline PMSG stator resistance & $0.672 \Omega$ \\
\hline PMSG stator inductance \\
$\left(L_{d}, L_{q}\right)$ & $13.47 \mathrm{mH}, 13.47 \mathrm{mH}$ \\
\hline PMSG flux & $2.39 \mathrm{~Wb}$ \\
\hline Pole pairs & 12 \\
\hline Turbine inertia & $30 \mathrm{kgm}^{2}$ \\
\hline Turbine type & 0.4 \\
\hline Maximum $C_{p}$ & $20 \mathrm{rad} / \mathrm{s}$ \\
\hline Maximum rotor speed & $4 \mathrm{~m} / \mathrm{s}$ \\
\hline Cut-in wind speed & horizontal axis turbine \\
\hline
\end{tabular}

Table 3 Control parameters in simulation

\begin{tabular}{|c|c|}
\hline Parameters & Values \\
\hline$a$ in (12) & $4 \mathrm{e}-5$ \\
\hline Initial $\theta$ & $10^{\circ}$ \\
\hline$n$ in $(22)$ & 4 \\
\hline$m$ in $(26)$ & 50 \\
\hline$\theta_{f}$ in $(28)$ & $2^{\circ}$ \\
\hline$\Delta \theta$ Threshold & $0.4^{\circ}$ \\
\hline
\end{tabular}

Simulation results are shown in Fig.7. At time 0 second, it is assumed that the wind turbine start-up period is over and the turbine already has an initial rotor speed. Before $t_{4}$, the system is in the training mode, where Figs.7(c)(d) show that $\theta$ increases gradually and $C_{p}$ approaches a maximum value with a rapidly fluctuating wind 
condition, as show in Fig.7(a). Fig.7(e) shows the rotor speed. The training mode takes less than 50 seconds, and then the system starts the routine mode once $\theta_{\text {opt }}$ settles.
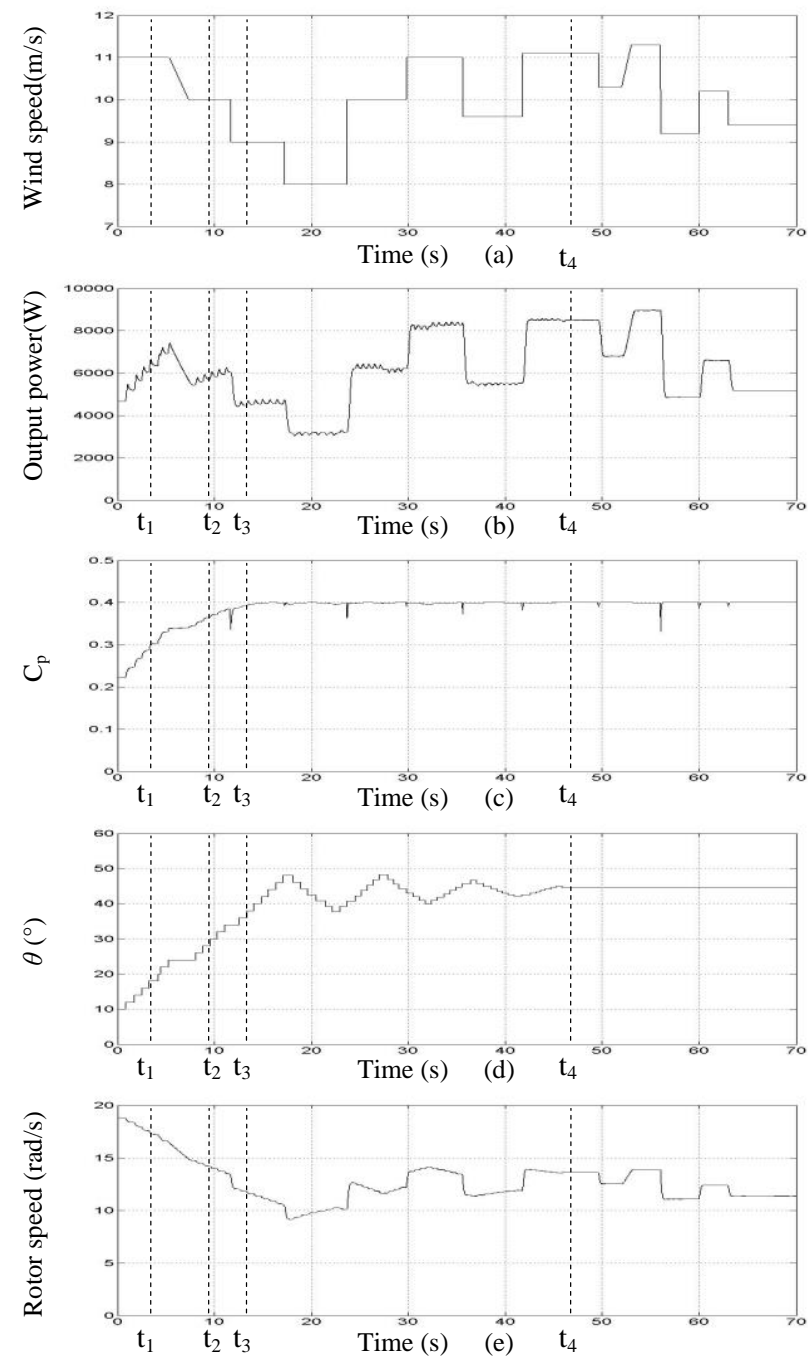

Fig.7 Simulation results of the proposed MPPT technique. (a) wind speed. (b) output power. (c) power coefficient. (d) angle, $\theta$. (e) rotor speed.

Between $t_{1}$ and $t_{2}$, the wind speed is unstable and reduces gradually as shown in Fig.7(a). In such an unstable wind condition, the controller in Section IV-A-2 guarantees that the $\mathrm{P} \& \mathrm{O}$ process does not operate. Fig. 8 shows the details of the $t_{1}$ to $t_{2}$ period. In Fig. $8(\mathrm{a})$, the wind speed gradually decrease from $12 \mathrm{~m} / \mathrm{s}$ to $10 \mathrm{~m} / \mathrm{s}$, and the output power reduces as well. Fig.8(d) shows that the $\mathrm{P} \& \mathrm{O}$ process stops and $\theta$ is fixed until the wind is stable again. It also shows that although the $\mathrm{P} \& \mathrm{O}$ process is not 
operational, the power efficiency, $C_{p}$, having been achieved does not decrease, as shown in Fig.8(c).
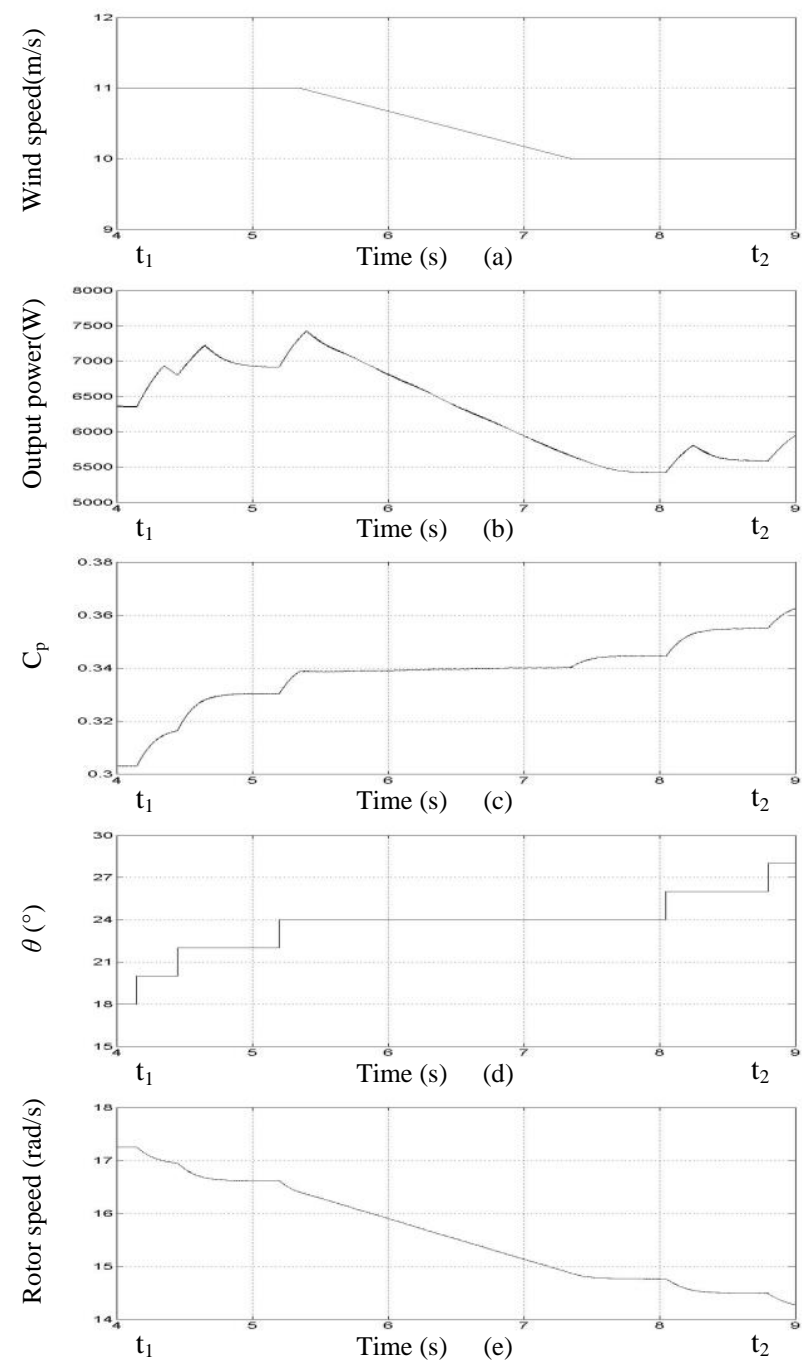

Fig.8 The detail simulation results of $t_{1}-t_{2}$ period. (a) wind speed. (b) output power. (c) power cofficient. (d) angle, $\theta$. (e) rotor speed.

During $t_{2}$ to $t_{3}$ shown in Fig.7, there is a sudden wind speed drop immediately after the $\theta$ adjustment. The details are shown in Fig.9. Fig.9(d) shows that at $t_{a}, \theta$ increases a $\Delta \theta$ value, but suddenly at $t_{b}$ the wind speed drops from $10 \mathrm{~m} / \mathrm{s}$ to $9 \mathrm{~m} / \mathrm{s}$. In Fig.9(b), the output power decreases thereafter. The control in Section IV-A-3 assures that the system is not 'fooled' by such a sudden speed change. As shown in Fig.9(d) once the wind speed is stable again at $t_{c}, \theta$ increases. 

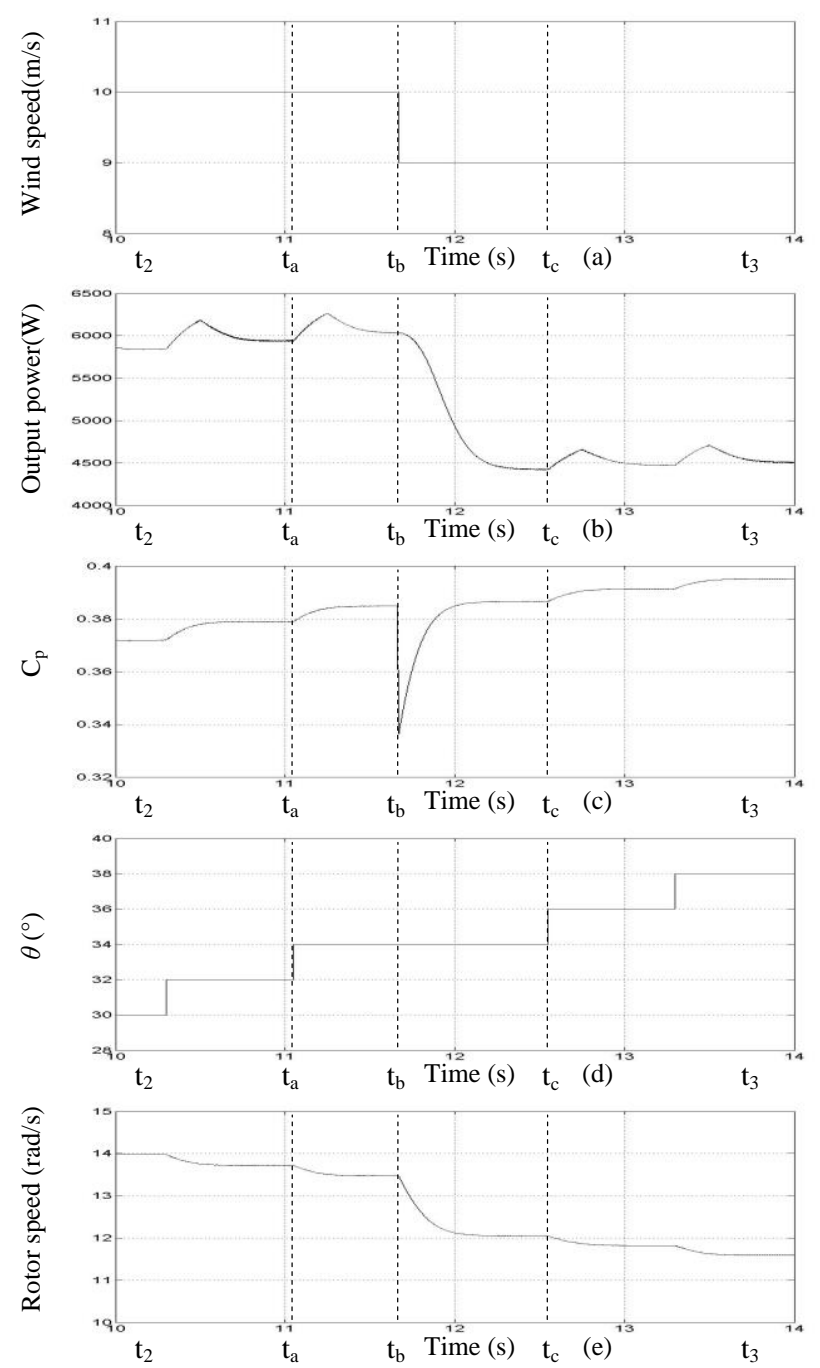

Fig.9 The detail simulation results of $t_{2}-t_{3}$ period. (a) wind speed. (b) output power. (c) power coefficient. (d) angle, $\theta$. (e) rotor speed.

Between $t_{3}$ and $t_{4}$ shown in Fig.7, $\theta$ is close to $\theta_{\text {opt }}$, and it starts to oscillate. The details are shown in Fig.10. From $t_{3}$ to $t_{4}, \theta$ oscillates with gradually reducing amplitude. Meanwhile, the total oscillating band decreases, which is shown in Fig.10(d) between $25 \mathrm{~s}$ and 50s. Although $\theta$ is oscillating, the power and $C_{p}$ is relatively stable as shown in Fig.10(a) and (c). This is due to the aforementioned flat-topped $C_{p}$ curve. The rotor speed is shown in Fig.10(e) 

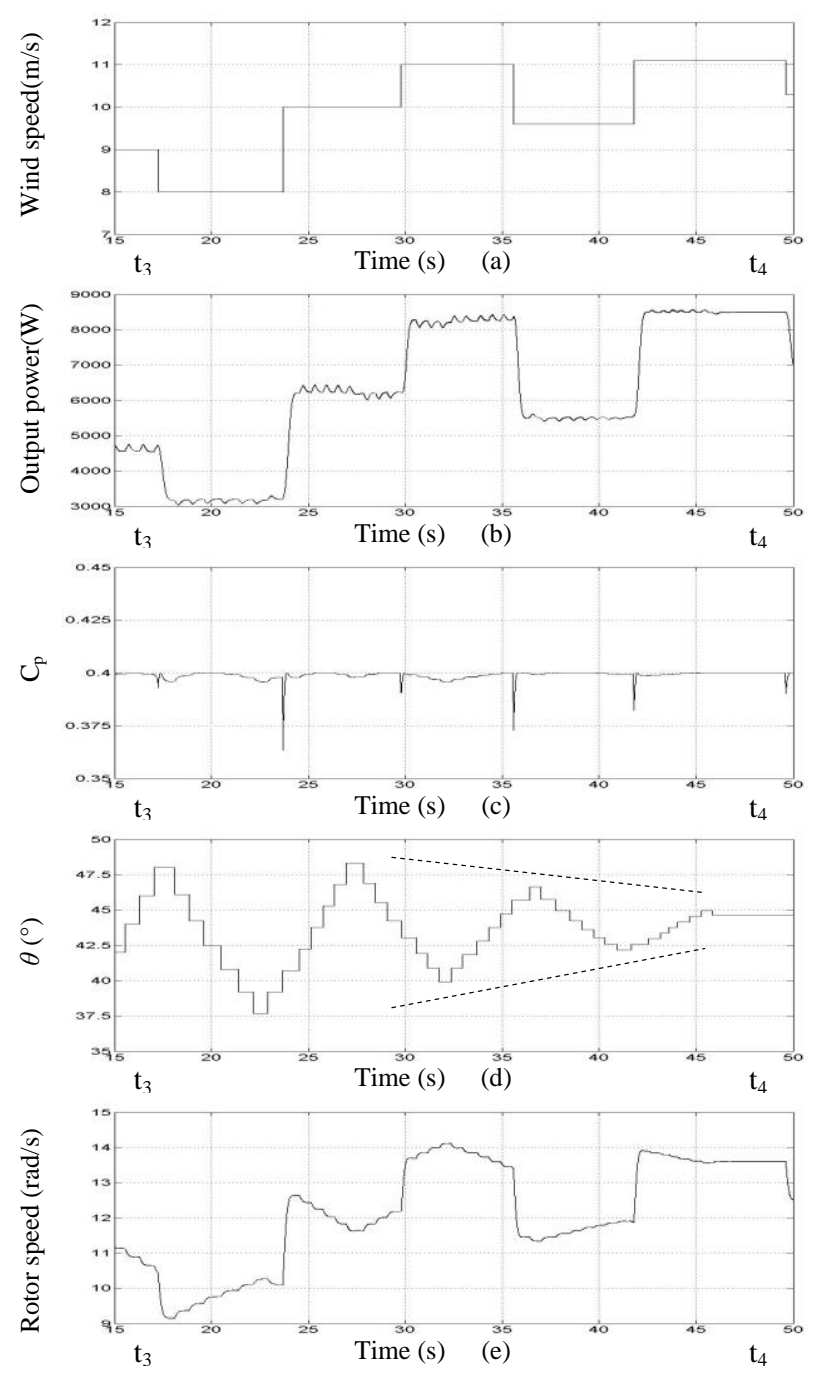

Fig.10 The detail simulation results of $t_{3}-t_{4}$ period. (a) wind speed. (b) output power.

(c) power efficiency. (d) angle, $\theta$. (e) rotor speed.

At $t_{4}, \theta$ finally converges to the optimum value as shown in Fig.7. The total time required for the training mode of the $10 \mathrm{~kW}$ system is less than 50s. Moreover, it also shows that $C_{p}$ approaches close to the maximum value in about $15 \mathrm{~s}$. This proves that the advance $\mathrm{P} \& \mathrm{O}$ process can obtain the optimum relationship in a short time. After $t_{4}$, the training mode ends, and the routine mode starts. The details are shown in Fig.11. The system is controlled by conventional ORB control and shows a fast response and good performance. 

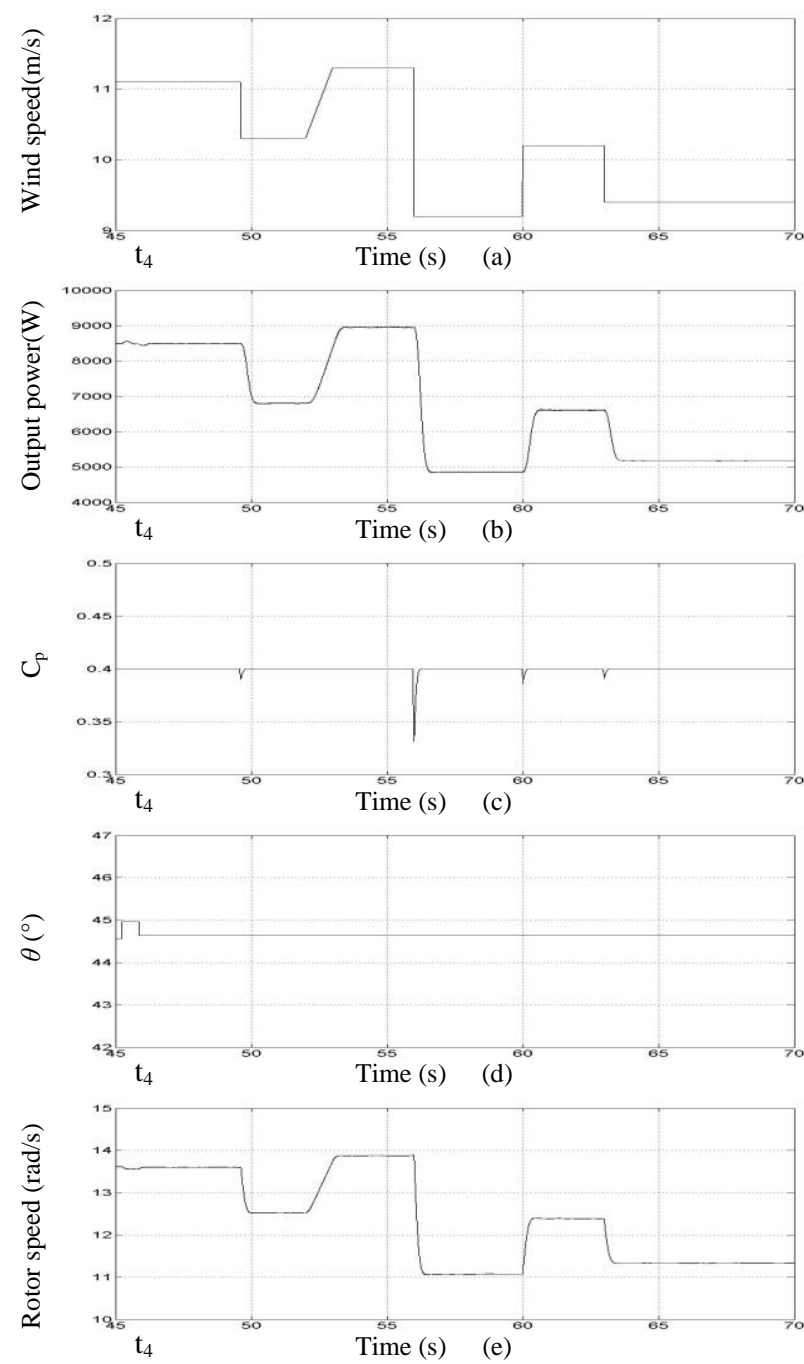

Fig. 11 The detail simulation results of routine mode after $t_{4}$. (a) wind speed. (b) output power. (c) power efficiency. (d) angle, $\theta$. (e) rotor speed.

\section{Experimental results}

A wind energy conversion system test rig shown in Fig.12 is used to verify the proposed MPPT technique. A $2.5 \mathrm{~kW}$ induction machine is controlled as a wind turbine. The rotor speed is sensed by the DSP, and a corresponding torque signal is given to control the machine through a power drive converter. A $2.5 \mathrm{~kW}$ PMSG is driven by the induction machine to provide output electrical power. The diode rectifier converts the output $\mathrm{AC}$ power from the generator into DC. The boost converter regulates the DC side voltage and current to track the maximum power 
point. The boost output voltage is maintained constant by a switch to model a constant voltage DC link. The system parameters are summarized in Table 4, and the control parameters are summarized in Table 5.

Table 4 Experimental system parameters

\begin{tabular}{|c|c|}
\hline Items & Specification \\
\hline $\begin{array}{c}\text { Induction machine power } \\
\text { rating }\end{array}$ & $2.5 \mathrm{~kW}$ \\
\hline Driver type & Emerson Unidrive \\
\hline PMSG power rating & $2.5 \mathrm{~kW}$ \\
\hline PMSG rated current & $7.4 \mathrm{~A}$ \\
\hline PMSG rated voltage & $195 \mathrm{~V}$ \\
\hline PMSG stator inductance & $32 \mathrm{mH}$ \\
\hline PMSG stator resistance & $3 \Omega$ \\
\hline Pole pairs & 4 \\
\hline Maximum $C_{p}$ & 0.43 \\
\hline Maximum rotor speed & $40 \mathrm{rad} / \mathrm{s}$ \\
\hline
\end{tabular}

Table 5 Practical control parameters

\begin{tabular}{|c|c|}
\hline Parameters & Values \\
\hline$a$ in (12) & $2 \mathrm{e}-4$ \\
\hline Initial $\theta$ & $5^{\circ}$ \\
\hline$n$ in $(22)$ & 4 \\
\hline$m$ in $(26)$ & 50 \\
\hline$\theta_{f}$ in $(28)$ & $1^{\circ}$ \\
\hline$\Delta \theta$ Threshold & $0.2^{\circ}$ \\
\hline
\end{tabular}

The experimental results are shown in Fig.13. Fig.13a shows the variable wind speed. After the start-up period, the system is rotating at certain speed. At 0 second, the proposed MPPT technique is applied. From 0s to 30s, $\theta$ increases and $\mathrm{Cp}$ gradually approaches the maximum value, with a varying wind speed. From $30 \mathrm{~s}$ to $52 \mathrm{~s}, \theta$ oscillates with a gradually reducing $\Delta \theta$ value. After $52 \mathrm{~s}$, the training mode is complete. The optimum $\theta$ is determined by the proposed technique. Then the routine mode starts, and the practical results show that even with a variable wind speed, the system has a 
fast response and good performance. The results confirm the validity of the proposed MPPT technique.

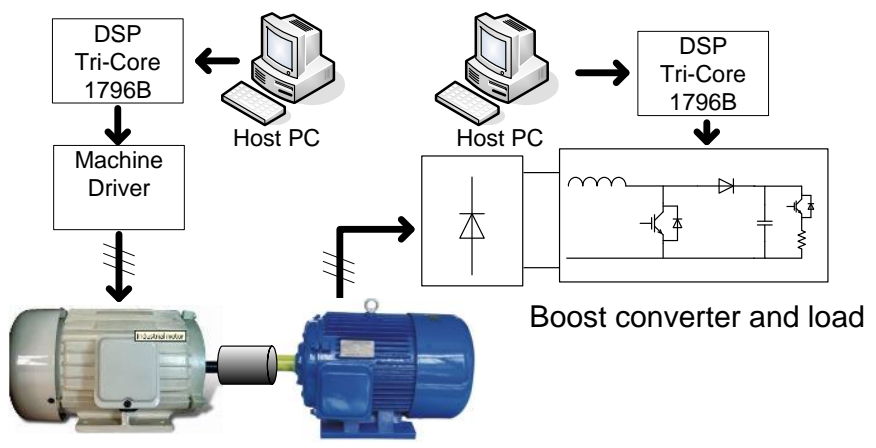

Fig.12 The wind energy conversion system test rig
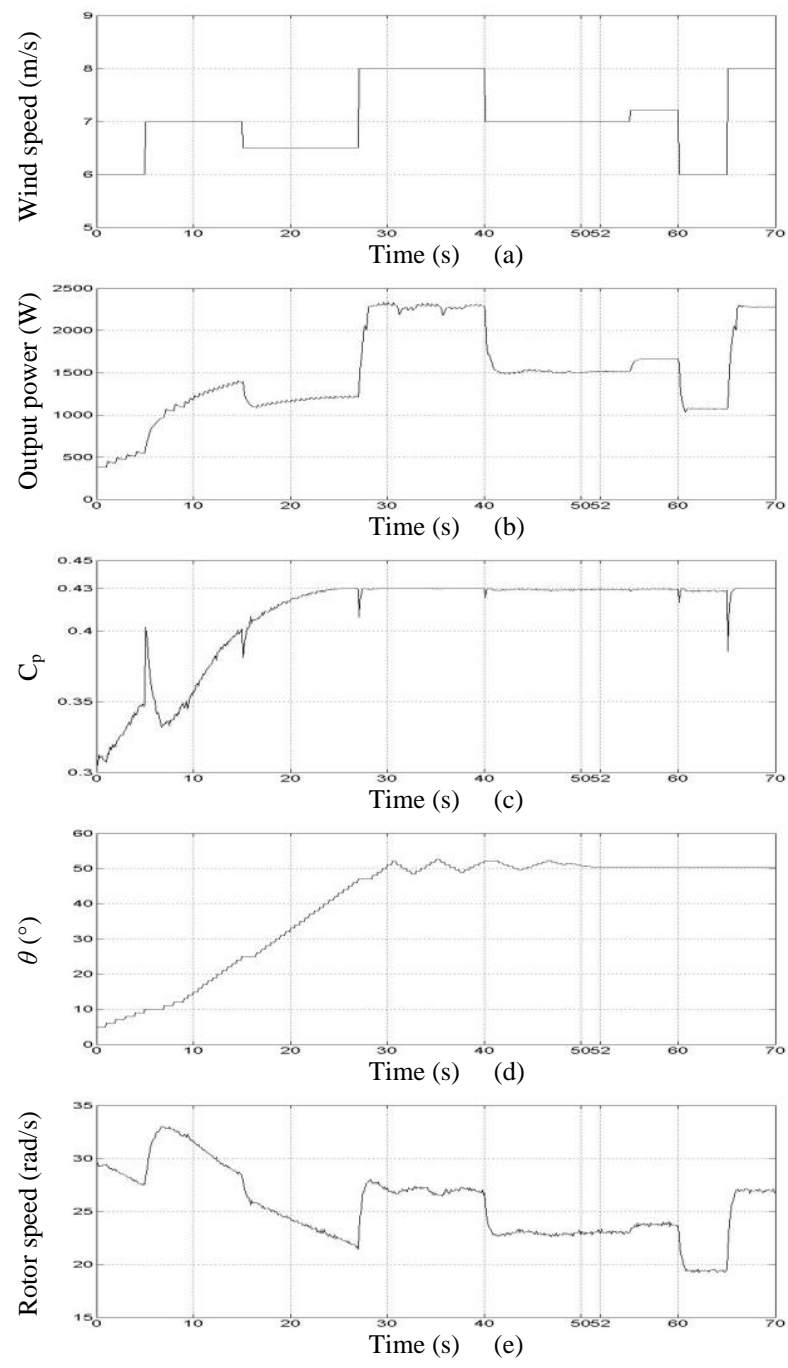

Fig.13 Experimental results. (a) wind speed. (b) output power.

(c) power coefficient. (d) angle, $\theta$. (e) rotor speed. 


\section{Discussion}

The proposed MPPT technique is presented and simulated for the WECS shown in

Fig. 2. However, this technique is a general method that can be applied to different topologies as long as the system satisfies equation (12). The power rating may be able to be extended to MW level. As the proposed MPPT technique searches for an optimum relationship rather than specific points, the system is controlled smoothly.

The concept of searching for an optimum relationship can be extended to the systems control based on optimum relationships such as $T=k_{1} \Omega^{2}$ [26], or $P=k_{2} \Omega^{3}$ [19], where $T$ is the electrical torque. As discussed, equation (12) is based on the assumption that the terminal voltage varies linearly with the turbine rotor speed, therefore the $C_{p}$ achieved may not be optimum for all wind speeds. However, when using the optimum relationship of $T=k_{1} \Omega^{2}$ and $P=k_{2} \Omega^{3}$ to control the system, the $C_{p}$ achieved may be nearer to optimum.

\section{Conclusion}

A new maximum power point tracking technique for permanent magnet synchronous generator based wind energy conversion systems has been proposed. The technique searches for the optimum relationship of the output rectified dc voltage and current in a short time during the training mode. An advanced $\mathrm{P} \& \mathrm{O}$ method was proposed to eliminate the effect of fluctuating wind conditions. Then the system is controlled based on this optimum relationship. Online updating can be implemented by running the search again. The proposed MPPT technique does not require an anemometer or the system pre-knowledge, but has an accurate and fast response to fluctuating wind speeds. MATLAB/Simulink simulation and practical results confirm the validity and 
performance of the proposed MPPT algorithm. Moreover, the proposed technique can be extended to systems with different topologies or based on other optimum relationships. 


\section{Reference}

[1] U.S. Energy Information Administration (EIA) Report \#: DOE/EIA-0484(2010), 2010.

[2] J. F. Manwell, J. G. McGowan, and A. L. Rogers, Wind Energy Explained. New York: Wiley, 2002, p. 88.

[3] Q. Wang, and L.-C. Chang, “An intelligent maximum power extraction algorithm for inverter-based variable speed wind turbine systems," IEEE Trans. Power Electron., vol. 19, no. 5, pp. 1242-1249, Sep. 2004.

[4] I. K. Buehring, and L. L. Freris, "Control policies for wind energy conversion systems," Proc. Inst. Elect. Eng. C, vol. 128, pp. 253-261, Sept. 1981.

[5] T.Thiringer, and J.Linders, "Control by variable rotor speed of a fixed-pitch wind turbine operating in a wide speed range," IEEE Trans. Energy Convers., vol. 8, no. 3, pp. 520-526, Sep. 1993.

[6] R. M. Hilloowala, and A. M. Sharaf, "A rule-based fuzzy logic controller for a PWM inverter in a stand alone wind energy conversion scheme," IEEE Trans. Ind. Appl., vol. 31, no. 1, pp. 57-65, Jan./Feb. 1996.

[7] R. Chedid, F. Mrad, and M. Basma, "Intelligent control of class of wind energy conversion systems," IEEE Trans. Energy Convers., vol. 14,pp. 1597-1604, Dec. 1999.

[8] K. Johnson, L. Fingersh, M. Balas, and L. Pao, "Methods for increasing region 2 power capture on a variable speed wind turbine," J. Solar EnergyEng., vol. 126, no. 4, pp. 1092-1100, 2004.

[9] K. E. Johnson, L. Y. Pao, M. J. Balas, and L. J. Fingersh, "Control of variablespeed wind turbines: Standard and adaptive techniques for maximizing energy capture," IEEE Control Syst. Mag., vol. 26, no. 3, pp. 70-81, Jun. 2006. 
[10] M. Ermis, H. B. Ertan, E. Akpinar, and F. Ulgut, "Autonomous wind energy conversion system with a simple controller for maximum-power transfer," IEE Proc. B, Electr. Power Appl., 1992, 139, (5),pp. 421-428.

[11] R. Datta and V. T. Ranganathan, "A method of tracking the peak power points for a variable speed wind energy conversion system," IEEE Trans. Energy Convers., vol. 18, no. 1, pp. 163-168, Mar. 1999.

[12] M. G. Simoes, B. K. Bose, and R. J. Spiegel, "Fuzzy logic based intelligent control of a variable speed cage machine wind generation system," IEEE Trans. Power Electron., vol. 12, pp. 87-95, Jan. 1997.

[13] M. G. Simoes, and B. K. Bose, "Design and performance evaluation of fuzzylogic-based variable-speed wind generation system," IEEE Trans. Ind. Appl., vol. 33, no. 4, pp. 956-965, Jul./Aug. 1997.

[14] E. Koutroulis, and K. Kalaitzakis, "Design of a maximum power tracking system for wind-energy-conversion applications," IEEE Trans. Ind. Electron., vol. 53, no. 2, pp. 486-494, Apr. 2006.

[15] M. R. Kazmi, H. Goto, H. Guo, and O. Ichinoku ra, “A Novel Algorithm for Fast and Efficient Speed-Sensorless Maximum Power Point Tracking in Wind Energy Conversion Systems," IEEE Trans. Ind. Electro., to be published.

[16] S. Bhowmik, R. Spée, and J. H. R. Enslin, "Performance optimization for doubly fed wind power generation systems," IEEE Trans. Ind. Applicat., vol. 35, pp. 949-958, July/Aug. 1999.

[17] A. M. Knight and G. E. Peters, "Simple wind energy controller for an expanded operation range,” IEEE Trans. Energy Convers., vol. 20, no. 2,pp. 459-466, Jun. 2005. 
[18] A. Neris, N. Vovos, and G. Giannakopaulos, "A variable speed wind energy conversion scheme for connection to weak ac systems," IEEE Trans. Energy Convers., vol. 14, no. 1, pp. 122-127, Mar. 1999.

[19] W. Lu and B. T. Ooi, "Optimal acquisition and aggregation of offshore wind power by multiterminal voltage-source HVDC," IEEE Trans. Power Del., vol. 18, no. 1, pp. 201-206, Jan. 2003.

[20] E. Muljadi and C. P. Butterfield, "Pitch-controlled variable-speed wind turbine generation,” IEEE Trans. Ind. Applicat., vol. 37, pp. 240-246,Jan./Feb. 2001.

[21] B. Shen, B. Mwinyiwiwa, Y. Zhang, and B.-T. Ooi, "Sensorless maximum power point tracking of wind by DFIG using rotor position phase lock loop (PLL)," IEEE Trans. Power Electron., vol. 24, pp. 942-951, Apr.2009.

[22] M. Chinchilla, S. Arnaltes, and J. C. Burgos, "Control of permanent-magnet generators applied to variable-speed wind-energy systems connected to the grid," IEEE Trans. Energy Conv., vol. 21,no. 1, pp. 130-135, Mar. 2006.

[23] A. Mirecki, X. Roboam, and F. Richardeau, "Architecture complexity and energy efficiency of small wind turbines," IEEE Trans. Ind. Electron., vol. 54, no. 1, pp. 660-670, Feb. 2007.

[24] K. Tan and S. Islam, “Optimum control strategies in energy conversion of PMSG wind turbine system without mechanical sensors," IEEE Trans. Energy Convers., vol. 19, no. 2, pp. 392-399, Jun. 2004.

[25] S. Morimoto, H. Nakayama, M. Sanada, and Y. Takeda, "Sensorless output maximization control for variable-speed wind generation system using IPMSG," IEEE Trans. Ind. Appl., vol. 41, no. 1, pp. 60-67,Jan./Feb. 2005.

[26] R. Pena, J. C. Clare, and G. M. Asher, "Doubly fed induction generator using back-to-back PWM converters and its application to variable speed wind-energy 
generation," Proc. Inst. Elect. Eng., Electr. PowerAppl., vol. 143, no. 3, pp. 231-241, May 1996.

[27] C.-T. Pan and Y.-L. Juan, "A novel sensorless MPPT controller for a highefficiency microscale wind power generation system," IEEE Trans. Energy Conversion, to be published.

[28] M. E. Haque, M. Negnevitsky, and K. M. Muttaqi, "A Novel Control Strategy for a Variable-Speed Wind Turbine with a Permanent-Magnet Synchronous Generator," IEEE Trans. Industry Applications, vol. 46, no. 1, pp. 331-339, Jan.-Feb. 2010.

[29] Z. Chen, and E. Spooner, "Grid power quality with variable-speed wind turbines," IEEE Trans. Energy Conv., vol. 16, no. 2, pp. 148-154, June 2001.

[30] S.-H. Song, S.-I. Kang, and N.-K. Hahm, "Implementation and control of grid connected ac-dc-ac power converter for variable speed wind energy conversion system," in Proc. IEEE APEC, vol. 1, pp. 154-158, 2003.

[31] H.-B. Zhang, J. Fletcher, N. Greeves, S. J. Finney, and B. W. Williams, “Onepower-point operation for variable speed wind/tidal stream turbines with synchronous generators", IET Renewable Power Generation, vol. 5, no. 1, pp. 99-108, Jan. 2011.

[32] H. Li, K. L. Shi, and P. G. McLaren, "Neural-network-based sensorless maximum wind energy capture with compensated power coefficient," IEEE Tran. Ind. Appl., vol. 41, no. 6, pp. 1548-1556, Nov./Dec. 2005.

[33] J. M. Carrasco, L. G. Franquelo, J. T. Bialasiewicz, E. Galvan,R. C. Portillo Guisado, M. A. M. Prats, J. I. Leon, and N.Moreno-Alfonso, "Power-electronic systems for the grid integration of renewable energy sources: A survey," IEEE Trans. Ind. Electron., vol. 53, no. 4, pp. 1002-1016, Jun. 2006. 
[34] J. A. Baroudi, V. Dinavahi, and A. M. Knight, “A review of power converter topologies for wind generators," Renew. Energy, vol. 32, no. 14, pp. 2369-2385, Nov. 2007.

[35] O. Anaya-Lara, N. Jenkins, J. Ekanayake, P. Cartwright, and M. Hughes, Wind Energy Generation: Modelling and Control. New York: Wiley,Sep. 2009.

[36] A. E. Fitzgerald, C. Kingsley, and S. D. Umans, Electric Machinery, Fifth ed: McGraw-Hill Book Company, 1992.

[37] M. H. Rashid, Power Electronics Circuits, Devices, and Applications. Englewood Cliffs, NJ: Prentice-Hall, 1993.

[38] T. F. Chan and L. L. Lai, "An axial-flux permanent-magnet synchronous generator for a direct-coupled wind turbine system," IEEE Trans. Energy Convers., vol. 22, no. 1, pp. 86-94, Mar. 2007.

[39] C. Liu, K. T. Chau, J. Z. Jiang, and L. Jian, "Design of a new outer-rotor permanent magnet hybrid machine for wind power generation," IEEE Trans. Magn., vol. 44, no. 6, pp. 1494-1497, Jun. 2008.

[40] G. D. Moor and H. J. Beukes, "Maximum power point trackers for wind turbines," in Proc. 35th Annu. IEEE Power Electron. Spec. Conf., Aachen,Germany, Jun. 2004, pp. 2044-2049.

[41] A. Tapia, G. Tapia, J. Ostolaza, and J. Saenz, "Modeling and control of a wind turbine driven doubly fed induction generator," IEEE Trans. Energy Convers., vol. 18, no. 2, pp. 194-204, Jun. 2003.

[42] M. H. Hansen, A. Hansen, T. J. Larsen, "Control design for a pitch-regulated, variable speed wind turbine”, Technical report, Risø National Laboratory. 2005 
[43] T.S. Mogensen, A.J. Larsen, N.K. Poulsen et al. "Design guidelines for integrated aeroelastic control of wind turbines". Technical report, Risø National Laboratory. 2006 